Case Study

\title{
Effects of consecutive application of stretching, Schroth, and strengthening exercises on Cobb's angle and the rib hump in an adult with idiopathic scoliosis
}

\author{
Jae-Man Yang, PT ${ }^{1,3)}$, Jung-Hoon Lee, PhD, PT²)* Dae-Hee Lee, PhD, PT ${ }^{3)}$ \\ 1) Department of Biomedical Health Science, Graduate School, Dong-Eui University, Republic of \\ Korea \\ 2) Department of Physical Therapy, College of Nursing and Healthcare Sciences, Dong-Eui University: \\ 176 Eomgwangno, Busanjin-gu, Busan 614-714, Republic of Korea \\ 3) Department of Physical Therapy, On General Hospital, Republic of Korea
}

\begin{abstract}
Purpose] To report the effects of consecutive application of stretching, Schroth, and strengthening exercises in an adult with idiopathic scoliosis. [Subject] A 26-year-old woman with idiopathic scoliosis, Cobb's angle of $20.51^{\circ}$, and back pain. [Methods] The exercise program consisted of 3 sessions: 10 minutes of stretching exercises, 20 minutes of Schroth exercises, and 10 minutes of strengthening exercises. This program was implemented 3 times a week, for 8 weeks. [Results] The thoracic Cobb's angle decreased from $20.51^{\circ}$ to $16.35^{\circ}$, and the rib hump decreased from $15^{\circ}$ to $9^{\circ}$. [Conclusion] Consecutive application of stretching, Schroth, and strengthening exercises may help reduce Cobb's angle and the rib hump in adults with idiopathic scoliosis.

Key words: Adam's forward bend test, Back pain, Rotational breathing
\end{abstract}

(This article was submitted Apr. 16, 2015, and was accepted May 15, 2015)

\section{INTRODUCTION}

Scoliosis is defined as a lateral spinal curvature with Cobb's angle of $10^{\circ}$ or more ${ }^{1)}$. Scoliosis usually develops before puberty and leads to a 3-dimensional trunk deformity ${ }^{2)}$. Compared to healthy individuals, patients with idiopathic scoliosis have decreased overall balance ${ }^{3)}$ and asymmetrical left-right transversus abdominis muscles ${ }^{4}$.

Lenssinck et al. ${ }^{5)}$ reported that exercise was the most effective conservative treatment for scoliosis, whereas Lee et al. $\left.{ }^{6}\right)$ stated that the core muscle release technique was the most effective. Schroth exercises are 3-dimensional exercises used for treating scoliosis, which were developed by Katharina Schroth in 19207); these provide sensorimotor and kinesthetic stimulation, thereby correcting abnormal breathing patterns present in patients with scoliosis. This program also includes training to help patients consciously maintain correct posture in daily living activities.

In this study, stretching, Schroth, and strengthening exercises were applied consecutively in an adult with idiopathic scoliosis to assess their effects on Cobb's angle and the rib hump.

*Corresponding author. Jung-Hoon Lee (E-mail: dreampt@ hanmail.net)

(C2015 The Society of Physical Therapy Science. Published by IPEC Inc. This is an open-access article distributed under the terms of the Creative Commons Attribution Non-Commercial No Derivatives (by-ncnd) License $<$ http://creativecommons.org/licenses/by-nc-nd/3.0/> .

\section{SUBJECT AND METHODS}

A 26-year-old woman diagnosed with idiopathic scoliosis and Cobb's angle $>20^{\circ}$ during her adolescence experienced back pain (visual analogue scale [VAS] score $=5$ ) and shortness of breath when climbing stairs. Her laboratory findings did not reveal anemia. She also reported twisting of her skirt to the right and developing creases only on the left side of her shirt. Prior to participating in the study, she demonstrated an understanding of its purpose and provided written informed consent. This study was conducted in accordance with the ethical standards of the Declaration of Helsinki.

The rib hump (difference in height between the right and left thorax) was $15^{\circ}$, as measured with the Adam's forward bend test using a scoliometer, during which the patient clasped her two hands together while in a standing posture, naturally dropped the hands between her legs, and bent forward to $90^{\circ 8}$ ), whereas Cobb's angle (the intersecting angle between the perpendiculars to the lines drawn parallel to the superior and inferior endplates of the most tilted vertebrae) ${ }^{9)}$ was $20.51^{\circ}$.

The exercise program used in this study consisted of 3 stages and was implemented 3 times a week, for 8 weeks. The first stage was a warm-up consisting of stretching for 10 minutes to relax the tightened muscles and improve joint flexibility. The second stage consisted of the Schroth exercises. Schroth breathing (rotational breathing), the most fundamental Schroth exercise, was used first to correct the breathing patterns, following which spine stabilization 
was induced through breathing activities corrected by the 3D-made-easy exercises. Finally, the patient was trained in the Schroth walking method to correct her posture while walking. The third stage was a cool-down phase consisting of 10 minutes of muscle strengthening exercises to activate the muscles corrected using the Schroth exercises and to maintain the skeletal frame.

\section{RESULTS}

After the 8-week intervention, Cobb's angle decreased from $20.51^{\circ}$ to $16.35^{\circ}(19.3 \%$ decrease $)$, and the rib hump decreased from $15^{\circ}$ to $9^{\circ}$ ( $40 \%$ decrease). The back pain rating decreased from VAS 5 to VAS 1; shortness of breath while climbing stairs disappeared; and the occurrence of her skirt twisting to the right and her shirt creasing only on the left side became less frequent.

\section{DISCUSSION}

In this study, consecutive application of stretching, Schroth, and strengthening exercises decreased the patient's Cobb's angle and rib hump. To treat scoliosis, the lengthened muscles should be shortened, and the shortened muscles should be lengthened again to restore the spine's vertical axis. Therefore, the stretching exercises implemented in the first stage may have relaxed the muscles that were asymmetrically shortened around the spine and lengthened the trunk, thereby increasing flexibility. Zakaria et al. ${ }^{10)}$ showed that stretching exercises decreased muscle spasms on the concave side and hyperactivity and corrected the curvature of the lumbar region by lengthening the shortened muscles.

Respiratory dysfunction is one of the major symptoms in patients with scoliosis ${ }^{11)}$. Changes in the chest wall and spine structure are associated with early onset scoliosis, which includes spine rotation, chest wall distortion, and a rib hump ${ }^{12)}$. Abnormal rib alignment may also affect thoracic rigidity and $\operatorname{size}^{13)}$. In addition, loss of elasticity of the costovertebral joints and spine can impair respiratory mechanics ${ }^{12}$. The Schroth exercises implemented in the second session comprise a program based on sensorimotor and kinesthetic principles that promote the correction of asymmetric posture and maintain correct posture through breathing activities ${ }^{14)}$. Rotational breathing, one of the Schroth exercises, was used to selectively contract the convex area of the trunk and allow the inspired air to move toward the concave areas of the ribs and thorax ${ }^{15)}$. Thus, rotational breathing may have corrected her breathing patterns, and the 3D-made-easy exercises may have remedied her breathing activities. Additionally, improvement in vital capacity secondary to performing the Schroth exercises may have improved her breathing while climbing stairs.

Furthermore, to avoid supporting the posture only with the spinal ligaments, the trunk was elevated through activation of its muscles, and the patient was trained to maintain the corrected posture during her daily living activities ${ }^{15)}$. Otman et al. ${ }^{15)}$ implemented Schroth exercises for a year in 50 adolescent patients with right thoracic scoliosis (4 hours per session, 5 times per week, for the first 6 weeks, after which the exercises were continued 90 minutes each day at home) and found that Cobb's angle was decreased from $26.10^{\circ}$ to $23.45^{\circ}$ after 6 weeks, to $19.25^{\circ}$ after 6 months, and to $17.85^{\circ}$ after 1 year.

The strengthening exercises implemented in the final stage activated the muscles that were corrected using the Schroth exercises and may have helped the patient maintain spinal stability by strengthening the trunk muscles. Zakaria et al. ${ }^{10)}$ reported that the use of strengthening exercises for the weakened muscles on the convex side corrected the body's line of gravity and improved muscle balance.

Back pain is a common symptom, occurring in $60-80 \%$ of adult patients with scoliosis ${ }^{16)}$. Although back pain is not directly related to the magnitude of the spine curvature, rotational subluxation and sagittal disproportion may increase back pain ${ }^{17,18)}$. In addition, the patient showed sagittal and coronal disproportion, which is customary in adults with scoliosis; this causes bad posture, which may lead to back pain $^{18)}$. Therefore, changing the spine structure by performing consecutive stretching, Schroth, and strengthening exercises may have decreased Cobb's angle and back pain in our patient.

This study had the following limitations. First, although the 8-week consecutive application of stretching, Schroth, and strengthening exercises decreased Cobb's angle and back pain, we were not able to perform a comparative analysis to determine whether this program was more effective than other treatments, since it was a single case study. Second, we were not able to conduct a long-term intervention for 6 months or 1 year to further reduce the patient's scoliosis. Therefore, a comparative study on the individual clinical effects of stretching, Schroth, and strengthening exercises in patients with idiopathic scoliosis is required.

\section{REFERENCES}

1) Green BN, Johnson C, Moreau W: Is physical activity contraindicated for individuals with scoliosis? A systematic literature review. J Chiropr Med, 2009, 8: 25-37. [Medline] [CrossRef]

2) Mooney V, Gulick J, Pozos R: A preliminary report on the effect of measured strength training in adolescent idiopathic scoliosis. J Spinal Disord, 2000, 13: 102-107. [Medline] [CrossRef]

3) Park JY, Park GD, Lee SG, et al.: The effect of scoliosis angle on center of gravity sway. J Phys Ther Sci, 2013, 25: 1629-1631. [Medline] [CrossRef]

4) Linek P, Saulicz E, Wolny T, et al.: Ultrasound evaluation of the symmetry of abdominal muscles in mild adolescent idiopathic scoliosis. J Phys Ther Sci, 2015, 27: 465-468. [Medline] [CrossRef]

5) Lenssinck ML, Frijlink AC, Berger MY, et al.: Effect of bracing and other conservative interventions in the treatment of idiopathic scoliosis in adolescents: a systematic review of clinical trials. Phys Ther, 2005, 85: 1329_ 1339. [Medline]

6) Lee M, Hwang J, Seo B, et al.: The effects of the core muscle release technique on scoliosis. J Phys Ther Sci, 2013, 25: 445-448. [CrossRef]

7) Lehnert-Schroth C: Three-dimensional Treatment for scoliosis. A physiotherapeutic method to improve deformities of the spine. Palo Alto: The Martindale Press, 2007.

8) Côté P, Kreitz BG, Cassidy JD, et al.: A study of the diagnostic accuracy and reliability of the Scoliometer and Adam's forward bend test. Spine, 1998, 23: 796-802, discussion 803. [Medline] [CrossRef]

9) Morrissy RT, Goldsmith GS, Hall EC, et al.: Measurement of the Cobb angle on radiographs of patients who have scoliosis. Evaluation of intrinsic error. J Bone Joint Surg Am, 1990, 72: 320-327. [Medline]

10) Zakaria A, Hafez AR, Buragadda, et al.: Stretching versus mechanical traction of the spine in treatment of idiopathic scoliosis. J Phys Ther Sci, 2012, 24: 1127-1131. [CrossRef]

11) Koumbourlis AC: Scoliosis and the respiratory system. Paediatr Respir Rev, 2006, 7: 152-160. [Medline] [CrossRef]

12) Redding GJ, Mayer $\mathrm{OH}$, Oscar $\mathrm{H}$, et al.: Structure-respiration function 
relationships before and after surgical treatment of early-onset scoliosis Clin Orthop Relat Res, 2011, 469: 1330-1334. [Medline] [CrossRef]

13) Campbell RM Jr, Smith MD, Mayes TC, et al.: The effect of opening wedge thoracostomy on thoracic insufficiency syndrome associated with fused ribs and congenital scoliosis. J Bone Joint Surg Am, 2004, 86-A: 1659-1674. [Medline]

14) Lehnert-Schroth $C$ : Introduction to the three-dimensional scoliosistreatment according to Schroth. Physiotherapy, 1992, 78: 810-814. [CrossRef]

15) Otman S, Kose N, Yakut Y: The efficacy of Schroth s 3-dimensional exer- cise therapy in the treatment of adolescent idiopathic scoliosis in Turkey. Saudi Med J, 2005, 26: 1429-1435. [Medline]

16) Grubb SA, Lipscomb HJ, Suh PB: Results of surgical treatment of painful adult scoliosis. Spine, 1994, 19: 1619-1627. [Medline] [CrossRef]

17) Weinstein SL, Dolan LA, Cheng JC, et al.: Adolescent idiopathic scoliosis. Lancet, 2008, 371: 1527-1537. [Medline] [CrossRef]

18) Glassman SD, Bridwell K, Dimar JR, et al.: The impact of positive sagittal balance in adult spinal deformity. Spine, 2005, 30: 2024-2029. [Medline] [CrossRef] 